\title{
Chemolitholyse: een vergeten optie voor de behandeling van cystine stenen
}

\author{
Kevin Hengstler ${ }^{1}$ Robert P. E. de Gier ${ }^{2}$ Michiel F. Schreuder ${ }^{1}$
}

Published online: 19 September 2016

(C) The Author(s) 2016. This article is available at SpringerLink with Open Access.

Samenvatting Een adolescente jongen met persisterende cystinestenen in de hoge urinewegen werd succesvol behandeld met chemolitholyse. Wij beschrijven een casus en presenteren een overzicht van de situaties waarin percutane chemolitholyse als behandeling kan worden toegepast.

Trefwoorden urolithiasis $\cdot$ cystinurie $\cdot$ chemolitholyse . percutaan

\section{Chemolitholysis: a forgotten approach in the management of cystine stones}

\begin{abstract}
An adolescent boy with persistent cystine stones in the upper urinary tract was successfully treated with chemolitholysis. We describe the case and provide an overview of the potential use of percutaneous chemolitholysis.
\end{abstract}

Keywords urolithiasis $\cdot$ cystinuria $\cdot$ chemolitholysis · percutaneous

\section{Introductie}

Cystinestenen komen voor bij circa 3-8\% van alle kinderen met urolithiasis in Europa [1]. De behandeling van uroli-

drs. Kevin Hengstler

kevin.hengstler@gmail.com

1 afdeling Kindernefrologie, Radboudumc Amalia Kinderziekenhuis, Nijmegen, Nederland

2 afdeling Urologie, Radboudumc Amalia Kinderziekenhuis, Nijmegen, Nederland thiasis bestaat in het algemeen uit extracorporal shockwave lithotripsy (ESWL), uretero(reno)scopie, percutane nefrolithotripsie (PNL) of nefrolithotomie. Wij presenteren een casus met persisterende cystinestenen in de hoge urinewegen om de aanvullende waarde te illustreren van behandeling met chemolitholyse bij nierstenen.

\section{Casus}

Een 16-jarige jongen presenteerde zich in een perifeer ziekenhuis met recidiverende koliekpijn in de rechterflank sinds vier jaar. Er werd een blanco CT-scan verricht, waarop meerdere nierstenen van verschillende grootte (maximaal $20 \mathrm{~mm}$ ) te zien waren in het linkernierbekken en een steen met een diameter van $9 \mathrm{~mm}$ halverwege de rechterureter. Vervolgens werden een ureteroscopie en lithotripsie verricht, waarbij meerdere stenen werden verwijderd: de op de CT-scan gesignaleerde steen halverwege de rechterureter, maar ook meerdere stenen uit het rechternierbekken, die op de eerdere CT-scan niet gezien waren. De stenen aan de linkerkant werden tijdens deze procedure niet verwijderd.

Bij analyse bleek de steen voor $100 \%$ uit cystine te bestaan. Hierop werd aan de patiënt het advies gegeven om veel te drinken $(3,51$ verdeeld over $24 \mathrm{u})$.

Twee maanden na de eerste lithotripsie werd de patiënt verwezen naar ons universitair medisch centrum. Daar werd een PNL verricht, waarbij alle stenen in het linkernierbekken werden verwijderd. Ook werd een steen halverwege de linkerureter gezien, maar deze kon niet worden verwijderd middels antegrade ureteroscopie. Aan het uiteinde van de PNL werd een nefrostomiekatheter achtergelaten om de urineafvloed te waarborgen. Naast de hoge vochtintake werd gestart met kaliumcitraat 3 d.d. $1000 \mathrm{mg}$ oraal, teneinde de 


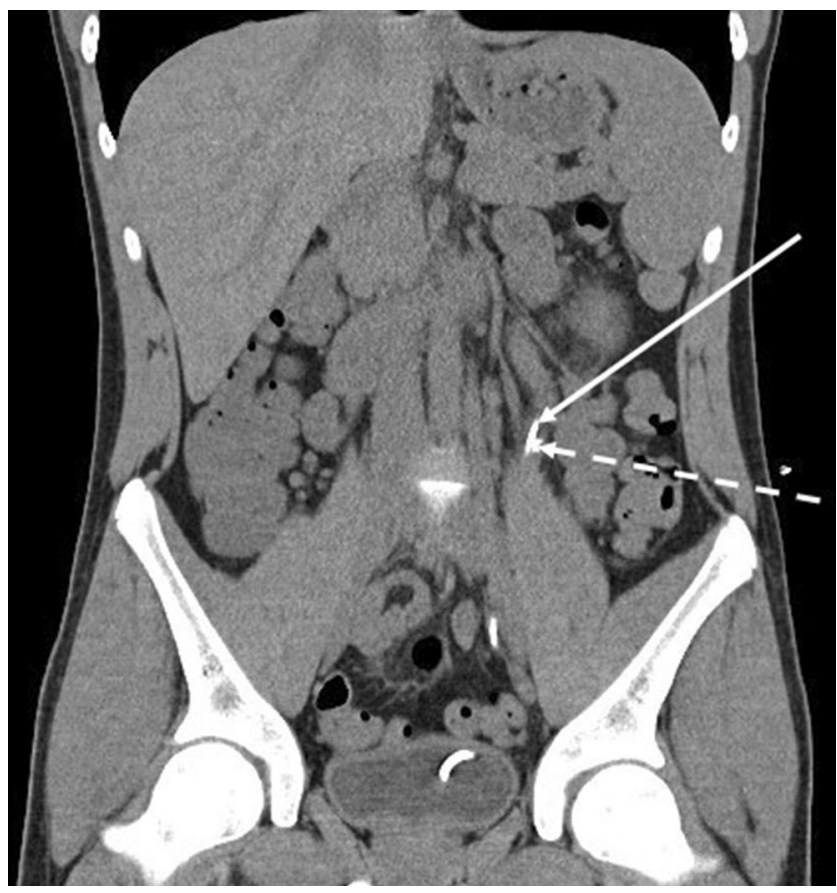

Figuur 1 CT-scan voorafgaand aan de behandeling met chemolitholyse. De ononderbroken pijl wijst naar dubbel-J-katheter, de onderbroken pijl naar de steen halverwege de linkerureter.

urine te alkaliniseren (streven naar een $\mathrm{pH}$ van 8 in verse urine) en hiermee de oplosbaarheid van cystine te vergroten [2].

Om de achtergebleven steen in de linkerureter te behandelen, werd twee weken na de PNL ESWL toegepast, maar deze was ineffectief.

Enige tijd daarna ontwikkelde patiënt een urosepsis op basis van een Klebsiella-infectie. Antibiotische behandeling hiervoor was effectief en twee maanden na de eerste PNL-behandeling werd een ureteroscopie met lithotripsie verricht, waarbij in totaal acht stenen werden verwijderd. Aan het eind van de procedure werd een dubbel-J-katheter geplaatst.

Zeven dagen na de ureteroscopie werd opnieuw een blanco CT-scan verricht ter evaluatie van eventuele reststenen. Hierbij werden meerdere kleine stenen en twee grotere stenen gezien in het linkernierbekken en een steen in de linkerureter, die een diameter hadden van respectievelijk 4, 5 en $7 \mathrm{~mm}$ (fig. 1). Om deze nierstenen te verwijderen, werd gestart met chemolitholyse, met als doel de stenen op te lossen. Via een nefrostomiekatheter werd een oplossing van $2 \%$ acetylcysteïne in $8,4 \%$ natriumbicarbonaat $(10 \mathrm{ml}$ acetylcysteïne $200 \mathrm{mg} / \mathrm{ml}$ in $90 \mathrm{ml}$ natriumbicarbonaat $8,4 \%$ ) toegediend, met een gemiddelde infusiesnelheid van $40 \mathrm{ml} / \mathrm{u}$ gedurende zeven dagen. Na de chemolitholyse werd voor de derde keer een CT-scan verricht, waarbij geen significante stenen meer werden gezien, noch in de nierbekkens, noch in de ureteren (fig. 2).

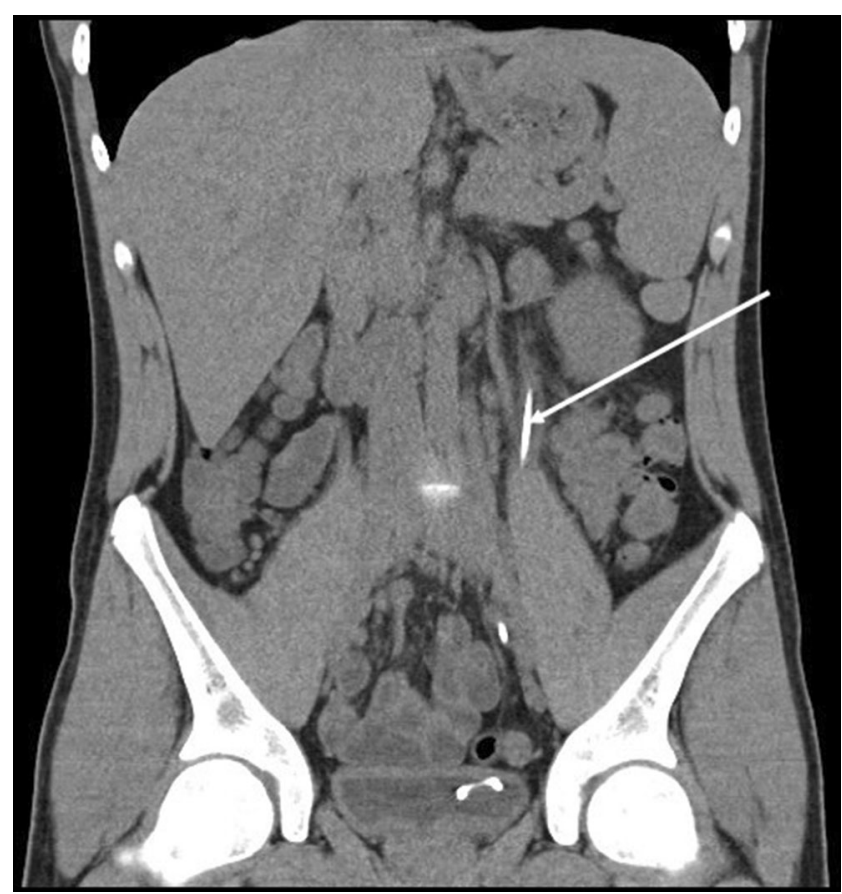

Figuur 2 Uit de CT-scan na de chemolitholyse blijkt de steen in de linkerureter (fig. 1) volledig opgelost. De ononderbroken pijl wijst naar de dubbel-J-katheter.

\section{Discussie}

Cystinurie en de vorming van cystinestenen treden secundair op aan een metabole stoornis in de proximale tubulus [2]. Cystine is relatief onoplosbaar in urine bij een fysiologische $\mathrm{pH}$ ( $\mathrm{pH}$ 5-7), maar bij een hogere $\mathrm{pH}$ neemt de oplosbaarheid toe [3, 4]. Bij deze patiënten moeten dan ook preventieve maatregelen worden genomen om de kans op de vorming van cystinestenen te minimaliseren. Een van die middelen is alkalinisatie, hoge vochtinname en een eiwitbeperkt dieet. Ter aanvulling kan medicatie worden voorgeschreven, zoals thiolderivaten (D-Penicillamine), alphamercaptopropionylglycine ( $\alpha-\mathrm{MPG}$ ) of captopril. Deze medicatie bevat een thiolgroep (zwavelwaterstof), die kan reageren met de disulfidebinding van cystine, een reactie die vervolgens leidt tot beter oplosbare complexen [4].

Hetzelfde principe geldt voor acetylcysteïne, maar deze stof wordt niet in de urine uitgescheiden na orale inname. Acetylcysteïne kan alleen met de disulfidebinding reageren wanneer het direct ter plaatse van de cystinestenen wordt toegediend. Chemolitholyse met acetylcysteïne (1-2\% in natriumbicarbonaat) is beschreven in meerdere studies [3-10]. Er is geen algemene consensus over de optimale dosering. Onderzoek van Jacobs et al. laat zien dat door de toevoeging van natriumbicarbonaat het oplossend vermogen van acetylcysteïne voor cystinestenen in een experimentele omgeving toeneemt [3]. In de richtlijn voor urolithiasis van de European Association of Urology (EAU) uit 2013 
Tabel 1 Overzicht van opties voor chemolitholyse bij stenen met verschillende samenstelling volgens de EAU Guidelines on Urolithiasis [10].

\begin{tabular}{|c|c|}
\hline steensamenstelling & oplosmiddel [10] \\
\hline struviet & $10 \%$ hemiacidrine, $\mathrm{pH} 3,5-4$; Solutio $\mathrm{G}$ \\
\hline cystine & $\begin{array}{l}\text { trihydroxymethyl aminomethaan (THAM; } 0,3-0,6 \mathrm{~mol} / \mathrm{l}), \mathrm{pH} 8,5-9 \\
N \text {-acetylcysteïne }(200 \mathrm{mg} / \mathrm{l})\end{array}$ \\
\hline urinezuur & THAM $(0,3-0,6 \mathrm{~mol} / \mathrm{L}), \mathrm{pH} 8,5-9$ \\
\hline
\end{tabular}

wordt chemolitholyse beschreven voor verschillende stenen (tab. 1; [10]). In deze richtlijn wordt aanbevolen om voor een optimaal effect bilateraal een nefrostomiekatheter te plaatsen. Deze casus laat echter zien dat ook bij gebruik van een unilaterale nefrostomiekatheter een goed effect bereikt kan worden.

Chemolitholyse kan worden toegepast voor stenen van magnesiumammoniumfosfaat (struviet), urinezuur en cystine. Calciumoxalaatstenen kunnen niet veilig worden opgelost in vivo, omdat daarvoor sterke zuren gebruikt zouden moeten worden. Ethyleendiaminotetra-acetaat. (EDTA) werd wel gebruikt voor calciumoxalaatstenen, maar deze aanpak was maar matig succesvol en leidde vaak tot urotheelschade [5, 6]. Voor het oplossen van struvietstenen kan Solutio G (een oplossing gebaseerd op citroenzuur) of hemiacidrine worden gebruikt en voor urinezuurstenen natriumbicarbonaat of trihydroxymethyl aminomethaan (THAM) [5, 6, 10]. Voor cystinestenen wordt, naast acetylcysteïne, ook THAM geadviseerd $[3,5$, 10].

Een obstructie van de urinewegen bij neonaten en jonge kinderen kan worden veroorzaakt door stenen, maar kan ook het gevolg zijn van een schimmelbezoar (bijvoorbeeld Candida albicans). Deze bezoars kunnen worden gespoeld met een amfotericine-B-oplossing via een percutane nefrostomiekatheter als additionele behandeling naast intraveneuze antimycotica, zoals fluconazol [11].

\section{Conclusie}

Onze casus laat een succesvolle behandeling zien van (rest)cystinestenen door middel van chemolitholyse met $2 \%$ acetylcysteïne in $8,4 \%$ natriumbicarbonaat. Dit is een efficiënte, ofschoon invasieve behandeling, die geïmplementeerd zou kunnen worden in de behandeling van cystinestenen.

Open Access This article is distributed under the terms of the Creative Commons Attribution 4.0 International License (http:// creativecommons.org/licenses/by/4.0/), which permits unrestricted use, distribution, and reproduction in any medium, provided you give appropriate credit to the original author(s) and the source, provide a link to the Creative Commons license, and indicate if changes were made.

\section{Literatuur}

1. Rellum DM, Feitz WF, Herwaarden AE van, et al. Pediatric urolithiasis in a non-endemic country: a single center experience from the Netherlands. J Ped Urol. 2014;10(1):155-61.

2. Saravakos P, Kokkinou V, Giannatos E. Cystinuria: current diagnosis and management. Urology. 2014;83(4):693-9.

3. Jacobs D, Heimbach D, Müller S, et al. Chemolysis of Artificial Cystine Stones (BON (N)-STONES) in vitro using a new dissolution device: first results. J Endourol. 2000;14(5):451-4.

4. Ng CS, Streem SB. Contemporary management of cystinuria. J Endourol. 1999;13(9):647-51.

5. Dretler SP, Pfister RC. Percutaneous dissolution of renal calculi. Ann Rev Med. 1983;34(1):359-66.

6. Kachrilas S, Papatsoris A, Bach C, et al. The current role of percutaneous chemolysis in the management of urolithiasis: review and results. Urolithiasis. 2013;41(4):323-6.

7. Aabech J, Andersen JT. Treatment of cystine stones: combined approach using open pyelolithotomy, percutaneous pyelolithotripsy, extracorporeal shock wave lithotripsy and chemolysis. Scand J Urol Nephrol. 1993;27(3):415-7.

8. Egghart G, Marquardt H-D, Kastert H, et al. Percutaneous nephrostomy and irrigation lithochemolysis a new concept for the treatment of cystine stones. Int Urol Nephrol. 1983;15(2):131-6.

9. Smith AD, Lange PH, Miller RP, et al. Dissolution of cystine calculi by irrigation with acetylcysteine through percutaneous nephrostomy. Urology. 1979;13(4):422-3.

10. Türk C, Knoll T, Petrik A, Sarica K, Skolarikos A, Straub M, Seitz C. EAU Guidelines on urolithiasis 2013. https://uroweb.org/wpcontent/uploads/21_Urolithiasis_LRV4.pdf. Geraadpleegd op: 13 juni 2016.

11. Visser DD, Monnens L, Feitz W, Semmekrot B. Fungal bezoars as a cause of renal insufficiency in neonates and infants - recommended treatment strategy. Clin Nephrol. 1998;49(3):198-201.

drs. Kevin Hengstler arts-assistent

drs. Robert P.E. de Gier uroloog

dr. Michiel F. Schreuder kindernefroloog 